\title{
Dietary B vitamin and methionine intakes and plasma folate are not associated with colorectal cancer risk in Chinese women
}

\author{
Martha J. Shrubsole ${ }^{1}$, Gong Yang ${ }^{1}$, Yu-Tang Gao ${ }^{2}$, Wang Ho $\mathrm{Chow}^{3}$, Xiao Ou Shu ${ }^{1}$, Qiuyin \\ Cai $^{1}$, Nathaniel Rothman ${ }^{3}$, Jin Gao ${ }^{2}$, Conrad Wagner ${ }^{4}$, and Wei Zheng ${ }^{1}$ \\ 1 Vanderbilt Epidemiology Center, Vanderbilt-Ingram Cancer Center, and Division of General Internal \\ Medicine and Public Health, Vanderbilt University, Nashville TN \\ 2Department of Epidemiology, Shanghai Cancer Institute, Shanghai, People's Republic of China \\ 3Division of Cancer Epidemiology and Genetics, National Cancer Institute, National Institutes of Health, \\ Department of Health and Human Services, Rockville, MD, USA
}

4Department of Biochemistry, Vanderbilt University School of Medicine, Nashville, TN

\section{INTRODUCTION}

Dietary factors involved in one-carbon metabolism may play a role in colorectal carcinogenesis (1). We evaluated whether dietary intakes of folate, methionine, and associated B vitamins were related to colorectal cancer risk using data from a large prospective cohort study of women in Shanghai, China. We further evaluated the relationship between baseline plasma folate levels and subsequent colorectal cancer risk in a nested case-control study from the same study population.

\section{MATERIALS AND METHODS}

The Shanghai Women's Health Study (SWHS) is a population-based prospective study of 74,942 Chinese women aged 40 to 70 years at cohort entry(2). Relevant committees for the use of human participants in research approved the study protocol and informed consent was obtained from all participants. All participants were interviewed using a validated food frequency questionnaire(3). The Chinese Food Composition Table was used to estimate daily intake levels of most nutrients. Methionine, vitamin B6, and vitamin B12 were derived using the United States Department of Agriculture food composition tables as previously described (4). The cohort was followed for cancer incidence and mortality by a combination of followup surveys and annual record linkage to cancer case data collected by the Shanghai Cancer Registry and death certificates collected by the Shanghai Municipal Center for Disease Control and Prevention (2). In order to allow for the delay in records processing, the date of the last follow-up was set as December 31, 2005 for study participants whose last in-person interview occurred before the censoring date, 6 months after the most recent record linkage (June 30, 2006). For the nested case-control study, cases were matched to controls (up to 4 per case) on age at baseline ( \pm 2 years), date ( $\leq 30$ days) and time (morning or afternoon) of blood collection, interval since last meal ( $\leq 2$ hours), menopausal status (pre- or post-), and antibiotic use (yes/

Address for correspondence: Martha J. Shrubsole, PhD, Vanderbilt Epidemiology Center, Division of General Internal Medicine and Public Health, Eighth floor, Suite 800, 2525 West End Avenue, Nashville, TN 37203-1738, Phone: (615) 936-0812, Fax: (615) 936-8288, email: E-mail: martha.shrubsole@vanderbilt.edu.

No author has any conflict of interest. 
no) in the past week. Baseline plasma folate levels were analyzed using the microbiological assay $(5,6)$.

\section{Statistical Analysis}

Nutrients were residual energy-adjusted (7). Cutpoints were based on the control distribution (nested case-control) or whole cohort (cohort analysis). The cohort analysis included 72,861 participants including 394 cases after excluding those with previous history of cancer $(n=1,490)$, unreasonably high or low energy intake $(n=132)$, or emigration from Shanghai shortly after baseline recruitment $(n=10)$. We estimated associations using hazard ratios $(\mathrm{HR})$ and $95 \%$ confidence intervals $(95 \% \mathrm{CI})$ derived from Cox proportional hazard regression models (8) stratifying on birth cohort (9). Stratified analyses were performed to evaluate potential effect modifiers. In the case-control analysis, conditional logistic regression analysis was used to estimate odd ratios and $95 \%$ CI. Tests for trend were performed by entering the categorical variables as continuous parameters in the models. $P$ values of $<0.05$ (2-sided probability) were interpreted as being statistically significant. Statistical analyses were conducted by using SAS statistical software (version 9.1; SAS Institute, Cary, NC).

\section{RESULTS}

Baseline characteristics of cohort members are previously published (2). Few women in this population ever smoked cigarettes, consumed alcoholic beverages, or used non-steroidal antiinflammatory medicines (data not shown). No statistically significant associations between dietary intakes of folate, methionine, and other B vitamins and colorectal cancer risk were observed (Table 1). Neither was any apparent association observed when limited to women who did not drink alcohol, women diagnosed with colorectal cancer more than two years after recruitment, women who did not use B vitamin supplements, pre-menopausal women, or postmenopausal women (data not shown in table).

The associations between dietary B vitamin and methionine intakes and colorectal cancer risk were similar in the nested case-control and cohort analyses. Plasma folate was not correlated with dietary methionine and $\mathrm{B}$ vitamin intakes among controls. The associations between plasma folate tertiles and colorectal cancer risk in the nested case-control study are presented in Table 2. Plasma folate was not associated with colorectal cancer risk overall nor when evaluated jointly with dietary intakes of methionine and B vitamins.

\section{DISCUSSION}

One carbon metabolism is important in several biological processes including methylation, DNA synthesis, and DNA repair. Folate and methionine are the major sources of dietary methyl groups and vitamin B6, vitamin B12, and riboflavin are important cofactors in one carbon metabolism. However, in our comprehensive evaluation of these factors, we found no evidence to support their associations with colorectal cancer risk.

The role of one carbon metabolism in colorectal cancer risk has been evaluated in previous studies with equivocal results. A recent meta-analysis of folate intake found that higher dietary but not total (including supplemental) folate intake was related to a modest decreased risk of colorectal cancer in both cohort and case-control studies (10). However, similar to our study, other studies published since the meta-analysis have largely reported null associations (1115), although one study observed an inverse relationship (16). Only a handful of nested casecontrol studies, none in a Chinese population, have evaluated biological measures of folate, including plasma folate (17-22), and most have reported a null association (19-22). These studies were mostly smaller and had lower folate levels than our study (17-20). Few studies 
have evaluated other dietary factors in one-carbon metabolism and colorectal cancer risk, and findings are also inconsistent (11,13-15,23-27).

In our study, we were able to evaluate a variety of factors related to one carbon metabolism in a population with no vitamin fortification of the food supply and low prevalence of alcohol use and vitamin supplement use. The prospective design, high participation rate, and high follow-up rates minimized the possibility of recall or selection bias. Since many foods which are rich in folate, such as green leafy vegetables, are also rich in other nutrients it is possible that nutrients other than folate and B vitamins or the interactions between these nutrients were responsible for previous observed associations or obscured associations in this study. It is also possible that the timing of our exposure assessment did not capture the relevant exposure window.

In summary, our study does not support a role for one carbon related dietary factors and plasma folate in the development of colorectal cancer in Chinese women.

\section{ACKNOWLEDGEMENTS}

The authors thank the research staff and participants of the Shanghai Women's Health Study. The project described was supported by grant R01CA70867 from the National Cancer Institute. The content is solely the responsibility of the authors and does not necessarily represent the official views of the National Cancer Institute or the National Institutes of Health

\section{References}

1. Strohle A, Wolters M, Hahn A. Folic acid and colorectal cancer prevention: molecular mechanisms and epidemiological evidence (Review). Int J Oncol 2005;26:1449-1464. [PubMed: 15870856]

2. Zheng W, Chow WH, Yang G, et al. The Shanghai Women's Health Study: rationale, study design, and baseline characteristics. Am J Epidemiol 2005;162:1123-1131. [PubMed: 16236996]

3. Shu XO, Yang G, Jin F, et al. Validity and reproducibility of the food frequency questionnaire used in the Shanghai Women's Health Study. Eur J Clin Nutr 2004;58:17-23. [PubMed: 14679362]

4. Shrubsole MJ, Jin F, Dai Q, et al. Dietary folate intake and breast cancer risk: results from the Shanghai Breast Cancer Study. Cancer Res 2001;61:7136-7141. [PubMed: 11585746]

5. Horne DW, Patterson D. Lactobacillus casei microbiological assay of folic acid derivatives in 96-well microtiter plates. Clin Chem 1988;34:2357-2359. [PubMed: 3141087]

6. Wilson SD, Horne DW. Use of glycerol-cryoprotected Lactobacillus casei for microbiological assay of folic acid. Clin Chem 1982;28:1198-1200. [PubMed: 6804123]

7. Willett WC, Stampfer MJ. Total energy intake: implications for epidemiologic analyses. Am J Epidemiol 1986;124:17-27. [PubMed: 3521261]

8. Hosmer, DW.; Lemeshow, S. Regression modeling of time to even data. New York: Wiley; 1999. Applied survival analysis.

9. Korn EL, Graubard BI, Midthune D. Time-to-event analysis of longitudinal follow-up of a survey: choice of the time-scale. Am J Epidemiol 1997;145:72-80. [PubMed: 8982025]

10. Sanjoaquin MA, Allen N, Couto E, et al. Folate intake and colorectal cancer risk: a meta-analytical approach. Int J Cancer 2005;113:825-828. [PubMed: 15499620]

11. Ishihara J, Otani T, Inoue M, et al. Low intake of vitamin B-6 is associated with increased risk of colorectal cancer in Japanese men. J Nutr 2007;137:1808-1814. [PubMed: 17585035]

12. Jiang Q, Chen K, Ma X, et al. Diets, polymorphisms of methylenetetrahydrofolate reductase, and the susceptibility of colon cancer and rectal cancer. Cancer Detect Prev 2005;29:146-154. [PubMed: 15829374]

13. Kune G, Watson L. Colorectal cancer protective effects and the dietary micronutrients folate, methionine, vitamins B6, B12, C, E, selenium, and lycopene. Nutr Cancer 2006;56:11-21. [PubMed: 17176213] 
14. Otani T, Iwasaki M, Hanaoka T, et al. Folate, vitamin B6, vitamin B12, and vitamin B2 intake, genetic polymorphisms of related enzymes, and risk of colorectal cancer in a hospital-based case-control study in Japan. Nutr Cancer 2005;53:42-50. [PubMed: 16351505]

15. Sharp L, Little J, Brockton NT, et al. Polymorphisms in the methylenetetrahydrofolate reductase (MTHFR) gene, intakes of folate and related B vitamins and colorectal cancer: a case-control study in a population with relatively low folate intake. Br J Nutr 2008;99:379-389. [PubMed: 18053312]

16. Larsson SC, Giovannucci E, Wolk A. A prospective study of dietary folate intake and risk of colorectal cancer: modification by caffeine intake and cigarette smoking. Cancer Epidemiol Biomarkers Prev 2005;14:740-743. [PubMed: 15767361]

17. Kato I, Dnistrian AM, Schwartz M, et al. Serum folate, homocysteine and colorectal cancer risk in women: a nested case-control study. Br J Cancer 1999;79:1917-1922. [PubMed: 10206314]

18. Van Guelpen B, Hultdin J, Johansson I, et al. Low folate levels may protect against colorectal cancer. Gut 2006;55:1461-1466. [PubMed: 16638790]

19. Glynn SA, Albanes D, Pietinen P, et al. Colorectal cancer and folate status: a nested case-control study among male smokers. Cancer Epidemiol Biomarkers Prev 1996;5:487-494. [PubMed: 8827351]

20. Rossi E, Hung J, Beilby JP, et al. Folate levels and cancer morbidity and mortality: prospective cohort study from Busselton, Western Australia. Ann Epidemiol 2006;16:206-212. [PubMed: 16343942]

21. Ma J, Stampfer MJ, Giovannucci E, et al. Methylenetetrahydrofolate reductase polymorphism, dietary interactions, and risk of colorectal cancer. Cancer Res 1997;57:1098-1102. [PubMed: 9067278]

22. Otani T, Iwasaki M, Sasazuki S, et al. Plasma folate and risk of colorectal cancer in a nested casecontrol study: the Japan Public Health Center-based prospective study. Cancer Causes Control 2008;19:67-74. [PubMed: 17943453]

23. Harnack L, Jacobs DR Jr, Nicodemus K, et al. Relationship of folate, vitamin B-6, vitamin B-12, and methionine intake to incidence of colorectal cancers. Nutr Cancer 2002;43:152-158. [PubMed: 12588695]

24. La Vecchia C, Negri E, Pelucchi C, et al. Dietary folate and colorectal cancer. Int J Cancer 2002;102:545-547. [PubMed: 12432561]

25. Flood A, Caprario L, Chaterjee N, et al. Folate, methionine, alcohol, and colorectal cancer in a prospective study of women in the United States. Cancer Causes Control 2002;13:551-561. [PubMed: 12195645]

26. Wei EK, Giovannucci E, Selhub J, et al. Plasma vitamin B6 and the risk of colorectal cancer and adenoma in women. J Natl Cancer Inst 2005;97:684-692. [PubMed: 15870439]

27. Theodoratou E, Farrington SM, Tenesa A, et al. Dietary vitamin B6 intake and the risk of colorectal cancer. Cancer Epidemiol Biomarkers Prev 2008;17:171-182. [PubMed: 18199722] 
Table 1

Associations between dietary intakes of methionine and B vitamins in the Shanghai Women's Health Study.

\begin{tabular}{|c|c|c|c|c|c|c|}
\hline & \multicolumn{5}{|c|}{ Quintiles of Dietary Intake } & \multirow{2}{*}{$\begin{array}{l}\mathbf{p} \text { for } \\
\text { trend }\end{array}$} \\
\hline & Q1 (low) & Q2 & Q3 & Q4 & Q5 (high) & \\
\hline \multicolumn{7}{|l|}{ Folate } \\
\hline Events, $\mathrm{n}$ & 76 & 89 & 64 & 82 & 83 & \\
\hline Mean Intake, $\mu \mathrm{g} /$ day & 213 & 235 & 269 & 318 & 419 & \\
\hline $\operatorname{HR}(95 \% \mathrm{CI})^{a}$ & $1.0(\mathrm{ref})$ & $1.3(1.0-1.8)$ & $1.0(0.7-1.4)$ & $1.2(0.8-1.7)$ & $1.1(0.8-1.7)$ & 0.78 \\
\hline \multicolumn{7}{|l|}{ Methionine } \\
\hline Events, $\mathrm{n}$ & 104 & 69 & 77 & 70 & 74 & \\
\hline Mean Intake, g/day & 1.26 & 1.28 & 1.39 & 1.58 & 2.07 & \\
\hline $\operatorname{HR}(95 \% \text { CI })^{a}$ & 1.0 (ref) & $0.8(0.6-1.1)$ & $1.0(0.7-1.4)$ & $1.0(0.7-1.5)$ & $1.2(0.8-1.8)$ & 0.27 \\
\hline \multicolumn{7}{|l|}{ Vitamin B12 } \\
\hline Events, $\mathrm{n}$ & 117 & 79 & 85 & 76 & 74 & \\
\hline Mean Intake, $\mu \mathrm{g} / \mathrm{day}$ & 1.28 & 1.69 & 2.22 & 2.93 & 4.86 & \\
\hline $\operatorname{HR}(95 \% \mathrm{CI})^{a}$ & 1.0 (ref) & $0.9(0.6-1.2)$ & $1.0(0.7-1.4)$ & $1.1(0.8-1.6)$ & $1.3(0.9-1.9)$ & 0.10 \\
\hline \multicolumn{7}{|l|}{ Vitamin B6 } \\
\hline Events, $\mathrm{n}$ & 97 & 72 & 76 & 85 & 64 & \\
\hline Mean Intake, mg/day & 1.36 & 1.44 & 1.59 & 1.80 & 2.33 & \\
\hline $\operatorname{HR}(95 \% \mathrm{CI})^{a}$ & 1.0 (ref) & $0.8(0.6-1.1)$ & $0.9(0.6-1.3)$ & $1.0(0.7-1.5)$ & $0.7(0.4-1.2)$ & 0.74 \\
\hline \multicolumn{7}{|l|}{ Niacin (B3) } \\
\hline Events, $\mathrm{n}$ & 97 & 74 & 72 & 75 & 76 & \\
\hline Mean Intake, mg/day & 12.9 & 12.5 & 13.1 & 14.4 & 18.3 & \\
\hline $\operatorname{HR}(95 \% \mathrm{CI})^{a}$ & $1.0(\mathrm{ref})$ & $0.8(0.6-1.2)$ & $0.9(0.6-1.3)$ & $1.0(0.7-1.4)$ & $1.0(0.7-1.6)$ & 0.68 \\
\hline \multicolumn{7}{|l|}{ Riboflavin (B2) } \\
\hline Events, $\mathrm{n}$ & 107 & 77 & 73 & 64 & 73 & \\
\hline Mean Intake, mg/day & 0.62 & 0.68 & 0.79 & 0.94 & 1.22 & \\
\hline $\operatorname{HR}(95 \% \mathrm{CI})^{a}$ & 1.0 (ref) & $0.9(0.6-1.2)$ & $0.9(0.6-1.3)$ & $0.9(0.6-1.3)$ & $1.1(0.7-1.9)$ & 0.69 \\
\hline
\end{tabular}

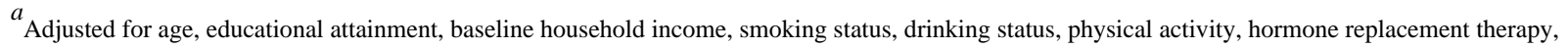
menopausal status, family history of colorectal cancer, body mass index (BMI), NSAID use, use of a B vitamin supplement, history of colorectal polyps, diabetes history, and daily intakes of energy, vegetables, fruits, red meats, and calcium. 
Table 2

Associations between colorectal cancer risk and plasma folate and joint plasma folate and dietary intake in a nested case-control study from the Shanghai Women's Health Study.

\begin{tabular}{|c|c|c|c|c|}
\hline & \multicolumn{4}{|c|}{ Plasma Folate Tertiles } \\
\hline & T1 (Low) & T2 & T3 & \\
\hline & $2.04-7.54 \mu \mathrm{g} / \mathrm{ml}$ & $7.55-11.09 \mu \mathrm{g} / \mathrm{ml}$ & $11.10-304.00 \mu \mathrm{g} / \mathrm{ml}$ & \\
\hline & OR $95 \%$ CI & OR $95 \%$ CI & OR $95 \%$ CI & $p$ for trend \\
\hline Cases & 96 & 95 & 112 & \\
\hline Controls & 396 & 396 & 396 & \\
\hline OR $95 \% \mathrm{CI}$ & $1.0(\mathrm{ref})$ & $1.0(0.7-1.3)$ & $1.2(0.8-1.7)$ & 0.30 \\
\hline Diet & & & & $\mathrm{p}$ for interaction \\
\hline \multicolumn{5}{|l|}{ Methionine } \\
\hline Low & $1.0(\mathrm{ref})$ & $0.9(0.6-1.4)$ & $1.2(0.8-1.9)$ & \\
\hline High & $1.0(0.6-1.6)$ & $1.0(0.6-1.6)$ & $1.1(0.7-1.9)$ & 0.52 \\
\hline \multicolumn{5}{|l|}{ Vitamin B12 } \\
\hline Low & $1.0(\mathrm{ref})$ & $0.9(0.6-1.5)$ & $1.1(0.7-1.7)$ & \\
\hline High & $0.9(0.6-1.5)$ & $0.9(0.6-1.5)$ & $1.2(0.8-2.0)$ & 0.69 \\
\hline \multicolumn{5}{|l|}{ Vitamin B6 } \\
\hline Low & $1.0(\mathrm{ref})$ & $0.6(0.4-1.0)$ & $1.3(0.8-2.0)$ & \\
\hline High & $0.8(0.5-1.3)$ & $1.1(0.7-1.8)$ & $1.0(0.6-1.6)$ & 0.40 \\
\hline \multicolumn{5}{|l|}{ Niacin (B3) } \\
\hline Low & $1.0(\mathrm{ref})$ & $0.7(0.4-1.1)$ & $1.2(0.7-1.8)$ & \\
\hline High & $0.6(0.4-1.0)$ & $0.8(0.5-1.3)$ & $0.8(0.5-1.3)$ & 0.50 \\
\hline \multicolumn{5}{|c|}{ Riboflavin (B2) } \\
\hline Low & $1.0(\mathrm{ref})$ & $0.8(0.5-1.3)$ & $1.0(0.7-1.6)$ & \\
\hline High & $0.9(0.5-1.5)$ & $1.0(0.6-1.6)$ & $1.2(0.7-2.0)$ & 0.75 \\
\hline
\end{tabular}

\footnotetext{
${ }^{a}$ Adjusted for age, educational attainment, baseline household income, smoking status, drinking status, physical activity, hormone replacement therapy, menopausal status, family history of colorectal cancer, body mass index (BMI), NSAID use, use of a B vitamin supplement, history of colorectal polyps, diabetes history, and daily intakes of energy, vegetables, fruits, red meats, and calcium.
} 